\title{
APONTAMENTOS SOBBRE O DIREITO COMERCIAL CONTEMPORÂNEO
}

PROF. PAULO BARBOSA LESSA

SUMARIO: 1. A legislação mercantil do após-guerra - 2. As três realidades fundamentais do momento: duas ordens econômicas, modificações no Ocidente e peculiaridades nacionais - 3. Enumeração das leis novas - 4. Significado dessa legislação -5 . Sua amplitude -6 . Prag. matismo - 7. Planejamento da economia -8 . Capitalismo financeiro - 9 Direito Tributário - 10 Normas previdenciárias - 11. Comércio internacional - 12, Capital estrangeiro - 13. Difusão da participação acionária - 14 . Títulos de crédito -15 . Direito concursal -16 . Tempo de semear.

1. O Direito Comercial brasileiro mereceu do legislador, após o término da Segunda Guerra Mundial, singular atenção. Na legislação extravagante do Código foram introduzidas modificaçōes de vulto. Sòmente o núcleo geral do velho diploma de $1850 \mathrm{se}$ mantém com a fisionomia com que chegara ao centenário. Ao lado do Direito Marítimo se mantêm a parte geral, o conceito de comerciante, as sociedades de pessoas, os contratos clássicos. Sabendo-se que a matéria de contratos é dispositiva e que a referente às sociedades de pessoas tradicionais vêm perdendo muito de sua primitiva transcendental importância, pode ver-se como e quanto, ao

* Titular de Direito Comercial. 
contrário de primeira impressão, a legislação mercantil se renovou. (1)

2. Direito pragmático por excelência, servo e por vêzes inspirador da economia, o Direito Comercial tem sido cadinho de experiências legislativas no setor privado. (2) No setor êsse suas figuras possuem caráter pioneiro. Neste século, marcado pelo sinal do relêvo dos temas econômicos, vão refletir-se no Direito Mercantil as transformações de base por que tem passado a sociedade mundial, o mundo capitalista ocidental e a comunidade brasileira.

Regulamentação jurídica progressista e informal, não se the podem compreender as normas abstraindo-as do concreto histórico. (3) Desde logo, contemporâneamente, deve adaptar-se a três realidades sociais, políticas e econômicas do mundo presente.

Há que levar-se em conta, primeiro, o aparecimento de uma oráem não capitalista privada. Bem que ainda separada por cortinas de ferro ou de bambu, econômica e espiritualmente essa ordem socialista ou capitalista de estado interfere no regramento dos problemas mercantis do chamado mundo ocidental. (4)

Segundo, no se dizente mundo ocidental grandes transformacões de espírito e de estruturas estão a operar-se como desdobramento das implicações de sua própria formulação, como imposição das conquistas da técnica, como adaptação à economia de mercado revolucionada pela rebelião das massas, como tentativa, mesmo, de superação do pensamento e da ordem predicadas pelas correntes marxistas. (5)

Terceiro, há de proclamar-se que no Brasil também se alterou o modo de sentir, de reagir e de pensar, em correspondência com

1. T. Ascarelli, Problemas das Sociedades Anônimas, S. Paulo, 1945 pg. 71; H. Estrêlla, O Código Comercial no Século, in Anais do Congresso do Cinquentenario da Faculdade de Direito de Porto Alegre, 1950, I, pg. 149; G. Ripert,

2. T. Ascarelli, Teoria Geral dos Títulos de Crédito, S. Paulo, 1943, pg. 3; Waldemar Ferreira, Instituições de Direito Comercial, S. Paulo, 1947, vol. I, pgs. 107/108.

3. P. Perlingieri, Produzione Scientifica e realtà pratica: una frattura da evitare, in Rivista del Diritto Commerciale, 1969, Parte Pri. meira pgs. 455 e segs.; A. Asquini, Rivista del Diritto Commerciale, vol. 25, pg. 516; G. Ferri, Manuale di Diritto Commerciale, Role, vol. 25, pg. 516 ,

4. G. Barraclough, Introdução à História Contemporânea, Rio, 1966, pg. 189.

5. W. Lippmann, A reconstrução da sociedade, Belo Horizonte, 1961, pg. 17; W. Röpke, La crisis social de nuestro tiempo, Madrid, 1956, pg. 169 segs. os anseios de progresso econômico, de industrialização, de recepção das conquistas da técnica, de superação do sub-desenvolvimento. (6)

Reflexo do mundo econômico, o Direito Comercial brasileiro está mudando porque a realidade econômica nacional também se alterou. Não é preciso ser profeta para saber-se que a mudança vai ser ainda mais acentuada.

3. Como é sabido, o Código Comercial fôra dividido em três partes fundamentais, além do Título Único, êste disciplinando a jurisdição especial ao comércio, ab-rogada ainda na fase imperial.

No período denominado de república velha, no mundo vitoriano que aqui sobreviveu talvez à Primeira Guerra Mundial, houve a substituição da Parte Terceira do Código referente a yuebras, das normas reguladoras das sociedades anônimas e das letras de câmbio e notas promissórias. Apareceram leis sôbre firmas, debêntures, cheques, responsabilidade civil das estradas de ferro. Surgiu a lei disciplinadora das sociedades por quotas de responsabilidade limitada. (7)

Ao tempo da Revolução de Trinta e do Estado Nôvo, houve copiosa legislação. Vieram leis sôbre Registro do Comércio, locacão de imóveis para fim comercial, falências, sociedades anônimas. Dois códigos sobrelevam: o do Ar, o da Propriedade Industrial. Apareceu a duplicata. (8)

Depois do término da Segunda Guerra Mundial, vem a fase dita contemporânea, sôbre a qual se deseja aqui chamar a atenção. Surgem, desde logo, naquele hiato de liberalismo que se seguiu ao conflito, as leis sôbre agências de informações, emprêsas de construção, reorganização do Tribunal Marítimo, alterações na legislação falimentar. Dêsse tempo é a lei que disciplinou a situação jurídica da mulher casada. (9)

Afinal, a multifária legislacão da Revolução. Disciplina renovada para Bôlsas e Registro de Comércio. Nôvo Código do $\mathrm{Ar}$, dois consecutivos Códigos da Propriedade Industrial. Modificações

6. K. Mannheim, Libertad, Poder y Planificación Democrática, Méxixico, 1960 pg. 45

7. Dec. 917, de 24.10.1890; D.434, de 4.7.1891, substituindo a L. 3150, de 4.11.1882; L. 2.044, de 31.12.1908. D. 916, de 24.10.1890; D $177-A$, de $15.9 .1893 ;$ D. 2591, de 7.8.1912; D. 2.681, de 7.12.1912; D. 3.708 , de 10.1 .1919 .

8. D. 24.635 , de 10.7 .1933 e D. 93, de 20.3.1935; D. 24.150, de 20.4.1934; DL 7661 , de 21.6 .1945 ; DL 2627 , de $26.9 .1940 ;$ DL 483 , de 8.6 . 1938; DL. 7903, de 27.8.1945. L. 187, de 15.1.1936.

9. L. 3.099 de $24.1957 ;$ L 4.068 de 29 6 1962; L 2180 de 5.2 .1954 ; L. 3.726 , de 11.2 .1960 L L 3.807 , de $26.8 .1960 ; \mathrm{L} .4 .421$, de 27.8 .1962 
mais amplas na Lei de Falências, disciplina mais completa sôbre liquidações extra-judicias de emprêsas econômicas. Leis sôbre mercado de capitais, com reflexo no campo do anonimato e das debêntures, lei sôbre duplicatas, lei sôbre representantes comerciais. Promulgação das Convenções de Genebra sôbre cheques, letras de câmbio e notas promissórias. Se a isso se somarem os reflexos da legislacão tributária e administrativa sôbre o Direito Mercantil, de importância notável, tem-se que, longe de ser velha a legislação comercial, foi assás renovada. (10)

4. Qual o significado dessa legislação mais recente?

Difícil é fazer-se balanço definitivo, mesmo porque estamos no centro do turbilhão, eis que as alterações se sucedem, em legiferação copiosa. Contudo, a tentativa de interpretarem-se as suas linhas gerais não é tarefa de desprezar-se. Valha desta tentativa pe. lo menos a afirmação de sua transcendental importância.

5. Ponha-se, de logo, em destaque a amplitude da legisla. ção recente, tanto em quantidade como em conteúdo. Da nominata das principais leis antes referidas bem pode notar-se essa amplitude. Os setôres mais fundamentais foram atingidos. Os títulos de crédito básicos tiveram sua disciplina modificada. Surgiram novos títulos no mercado imobiliário, e os títulos de crédito rurais foram reformulados. Todo um sistema de mercado de capitais se cristalizou, substituindo a espontaneidade das figurações anteriores. Houve relexos importantes em tema de concordatas. Também isso acontece no tocante à sociedade por ações, nos textos das leis sôbre mercado de capitais e na legislação tributária. Seguros, bancos e financeiras tiveram suas regulamentações atingiơas. Administrativamente, vieram a regulação dos registros do direito terrestre, marítimo e aeronáutico, da propriedade industrial, das bolsas. A primeira afirmação seja, pois, a de que as novas leis atingiram parte fundamental da matéria mercantil. (11)

10. Res. do B. Central 39, de 20.10.1966; L. 4.726, de 13.7.1965. DL. 32, de 18.11.1966; DL. 254, de 2.2.1967 e DL. n. 1005, de 21.10.1969. L. 4.839, de 18.11.1965; DL. 192, de 24.2.1967 e L. 4.893, de 18.5. 1966. L. 4.728, de 14.7.1965; L. 5.474, de 18.7.1968; L. 4.886, de 9.12.1965; D. 57.595, de 7.1.1966 e D. 57.663, de 24.1.1966. São leis básicas do Direito Tributário a L. 5.172, de 25.10.1966 e o DL. 406 , de 31.12 .1968 .

11. E, aliás, fenômeno mundial. P. ex., para o Direito das Sociedades, v. C. Stolfi, Il Diritto Francese delle Società, especialmente nota 1, in Rivista del Diritto Commerciale, 1968, Parte Primeira, pg. 226 e segs.
6. Inexiste nessa massa legislativa, contudo, diretriz teórica precieliberada. Respeitadas linhas fundamentais de economia pluralista, é o pragmatismo tônica dominante nessa legislação. (12) Os problemas complexos de um país que procura desenvolver-se, em mundo altamente técnico e no qual há competência 'xxtremada e nacionalismos exacerbados, são esquematizados sem preocupações ortodoxas, tornando-se difícil ao intérprete fixar as linhas dominantes através das quais evolui o sistema. Há modificações sentidas de orientações, por pressão de homens e de fatos. Há até fraturas, como a da aprovação das Convenções de Genebra sôbre títulos de crédito, $€ \mathrm{~m}$ bôa parte produto de compromisso histórico do mundo desaparecido de ante-guerra, vênia permitida, inserido com atraso em sistema nacional que em certo sentido já lhe era nìtidamente superior. Podem surpreender-se, entretanto, certas constantes nesse evoluir. E o que se tentará fazer.

7. Afirme-se, de pronto, o acentuar-se do planejamento da economia nacional, com o fortalecimento do unitarismo, em prejuízo da posição federativa do anterior momento histórico. Disso resulta que o mercado rompe as barreiras regionais. Há concentração das emprêsas, por absorção direta ou por participação em cadeia. Vinculam-se recursos públicos e particulares, em variada forma. Surgem os Bancos de Desenvolvimento Econômico, regionais, nacionais, até internacionais. Aparecem os incentivos fiscais, de influxos significativos na economia privada e no direito econômico por excelência, que é no mundo capitalista contemporâneo o Direito Comercial. (13)

8. Há, conseqüentemente, uma explosão de capitalismo financeiro, até então desconhecida no país. $\mathrm{O}$ mercado interno cresceu ràpidamente e diversificou-se. O fenômeno creditício transfigurou-se. Em uma década, o próprio homem comum podia sentir na carne que a economia se alterara e que as relações mercantis passavam a ser dirigidas pelas grandes concentrações financeiras. Improvisaram-se até organizações dêsse tipo, a aventura atraindo os audaciosos. Muitos, incompetentes ou sem escrúpulos, quebraram, com prejuízos à poupança de humildes. O Poder Público foi chamado, então, às vêzes com atraso, a regulamentar essa nova reali-

12. L. Lordi, Le Obbligazioni Commerciali, Milano, 1936, vol. I, pg. 4 e segs.; Fran Martins, Curso de Direito Comercial, Rio, 1958, pg. 31 13. F. Perroux, O capitalismo, Rio, 1961, pg. 133; Revista Visão, Agôsto 1970 (ed. especial), pg. 66; Celso Furtado, Formação Econômica do Brasil, Rio, 1959, pg. 279; R. Requião, S.A., Formas de Constituição de Seu Capital, in R. Tribunais, vol. 403 , pgs. 25 segs. 
dade, tutelando a economia popular e disciplinando as intrincadas prioridades setoriais da economia nacional em expansão. (14)

9. O influxo do sistema tributário sôbre o Direito Comercial contemporâneo é o responsável por outra diretriz da moderna matéria de aireito mercantil.(15) Impossível compreender a realidade do Direito Mercantil pátrio sem atender aos conexos mandamentos do Direito Tributário. Impôsto de renda, impôsto de circulação de mercadorias, impôsto sôbre produtos industrializados, impôsto de exportação, e mais, são realidades financeiras e conceitos jurídicos sempre presentes aos comerciantes e comercialistas, cujo esquecimento trará distorsões de funestos resultados. A noção segundo a qual o tributo é meio adequado de promover o desenvolvimento econômico tornou-se correntia. (16) E implica no reconhecimento do fim do liberalismo econômico puro. Como também na renovacão do direito que trata das emprêsas econômicas, poderosa entidade do mundo dos negócios contemporâneo, instrumento através do qual se está a processar êsse desenvolvimento.

10. O impacto do setor público no direito das emprêsas mercantis multiplica-se com a regulação dos serviços de previdência social. (17) Tem a organização dêsses serviços reflexos ponderáveis na vida da emprêsa. Nos últimos anos, longe de diminuírem, as contribuições para êsse setor previdenciário têm crescido. É que a distribuição social da riqueza nos sistemas econômicos pluralistas tem de fazer-se através do setor empresário, cuja vivência e atividade constituem a matéria fundamental do Direito Comercial do presente.

11. O desenvolvimento do país liga-se, sobremodo, às relacões de comércio internacional. (18) $\mathrm{O}$ incremento às exportações, a supervisão das importações, o afã de proteger a indústria nativa, produzem distorções no mecanismo da concorrência pura, hoje, talvez como sempre, inexistente no mundo das relações econômicas entre as nações. Normas dirigistas avolumam-se no setor.

14. O. Barreto Fọ, Regime Jurídico das Sociedades de Investimentos, S.Paulo, 1956, pg. 22; A. Birnie, História Econômica da Europa, Rio, 1964, pg. 104 e segs.; W.W. Rostow, Etapas do Desenvolvimento Econômico, Rio, 1961, pg. 70 .

15. J. Escarra, Manuel de Droit Commercial, Paris, 1947, pgs. 29 e 38.

16. F. Perroux, 0 capitalismo, cit., pg. 108 ( $\ll$ O impôsto nunca é neutro»); Geraldo Ataliba, Sistema Constitucional Tributário Brasileiro, S.Paulo, 1968, pg. 150 segs.; Ruy Barbosa Nogueira, Função Fiscal e Extra-Fiscal dos Impostos, R. Tribunais, vol. 380, pg. 32.

17. A. Birnie, cit. pg. 254 segs.

18. L. Erhard, Bem-Estar Para Todos, Rio, s/d, pg. 248; Celso Furtado, Formação Econômica do Brasil, cit. pg. 269.
O Direito Comercial tinge-se dessas normas ricas de atualidade, passando a fascinar cada vez mais as mentes do que desejam trabalhar com os olhos fixados no futuro.

12. Toca a matéria comercial do presente em tema pouco menos que explosivos por essência: a participação do capital es-

trangeiro no país. A legislação tem-se mostrado prudente no particular, oscilando, quanto à maior ou menor receptividade dessa intromissão, conforme os tempos e as personalidades dirigentes. $\mathrm{Re}$ leva notar que a experiência tem demonstrado ser o Poder Público a única fôrça interna com condições de dialogar com as potências a única fôrça interna com condiçôes da fragilidade do setor privado econômicas estrangeiras, em face da fragilidade do setor privado nacional em comparação com a pujança das empresas dos paíse desenvolvidos. A nacionalização dos serviços de base está a operar-se, continuamente. Petróleo, serviços públicos, transportes internacionais, energia, são setôres em que a atitude protecionista mostra-se judiciosamente ativa, sem preocupação maior com a ortodoxia de posições ideológicas. (19)

13. Há preocupação em difundir a participação do público no capital das sociedades anônimas. (20) A lei passou a diferenno capital aberto. (21) O fenômeno, que se iniciara no país quase à margem da lei, foi regulamentado primeiro através da fiscalização bancária, para finalmente obter a disciplina formal da legislação. A lei especial que reguto mercial vivo do país. Complementada por cambiantes regulamenmercial vivo do país. Complementada por cambiantes regulamentações bolsísticas, bancárias e tributárias, a disciplina da circulação dos valôres mercantis tomou, déctarta repercussão sôbre a matéria comercial.

14. A disciplina dos títulos de crédito revela, talvez com meos felicidade, a interligação das economias em plano supranacional. Promulgaram-se as Convenções de Genebra sôbre os títulos de crédito fundamentais. A disciplina dêsses títulos, pela contraditada implantação de um sistema que resultara do entrechoque de fôr-

19. Roberto O. Campos, Do Outro Lado da Cêrca, Rio, 1968, pg. 63; G. Vargas, na discutida e discutivel Carta-Testamento, in N. W. Sodre, Formacão Histórica do Brasil, Rio, 1964, pg. 412. Revista Visão, Ag. 1970 (ed. especial), pgs 308 a 311.

20. Berle e Means, A Propriedade Privada na Economia Moderna, Rio, 1957, pg. 17 e segs.

21. Lei 4.728 (Lei do Mercado de Capitais) art. 59 
ças políticas de um mundo inteiramente desaparecido, colheu de surpresa a vida dos negócios, tardando a fazer parte do direito vivo do país, além de criar controvérsias e incertezas de todo em todo indesejáveis. Além de sua vigência, é sua oportunidade discutida e discutível. (22)

A lei sôbre a duplicata mercantil revela pressões dos comerciantes para obter título executivo oriundo de operação mercantil, objetivo atingido com menor felicidade técnica. Reformas dêsse porte estão a merecer mais meditação ao serem realizadas. A bôa técnica legislativa é quase inseparável da bôa lei. (23)

15. Não às escâncaras se alteraram sensìvelmente normas de direito concursual, revelando setor que está a merecer talvez atenção ainda maior do legislador. (24) A própria lei de falências foi atingida, notadamente na parte referente às concordatas. Procurou mitigar-se o aventureirismo e a fraude que alimentavam o instituto, corrompido pela adiunção da morosidade de um sistema processual arcaico com o aviltamento das dívidas em moeda por infla. ção desenfreada. Mudança significativa resulta de proliferação de esquemas de liquidação extra-judicial, em tentativa de tutelar quer a economia popular, quer o prosseguimento das atividades organizaças, mediante transferências de fundos de comércio tais a entidades solventes, minimizando os prejúzos coletivos de reorganização.

16. O pragmatismo tem sido exacerbado, eis que à delegacão legislativa para o Executivo, direta ou indiretamente resultante do atual sistema constitucional,(25) se tem somado a delegação formal das leis aos sucedâneos mais expeditos dos decretos e regulamentos. (26) Matérias de reflexo importante na vida econômica e no sistema do direito que a modela são resolvidas por impulso ministerial, formalizando-se em decretos ou em simples regulamentos. Revela-se, destarte, para o mal ou para o bem, a aceleração legife-

22. José Maria Whitaker, in R. dos Tribunais, vol. 381, pg. 7; Rodolfo Araújo, in R. Forense, vol. 227, pg. 41; Fábio K. Comparato, in R.
dos Tribunais, vol. 390 , pg. 48 . Em sentido contrário Lélio pos, As Leis Uniformes de Genebra, P Alente, 1968 nio Mercado Jr. Cinco Estudos, S.Paulo, 1966, pg. 115 segs.

23. C.F.S. Peixoto, Comentários à Lei de Duplicatas, Rio, 1970, pgs, 33 e 118.

24. Fábio K. Comparato, Aspectos Jurídicos da Macro-Emprêsa, S. Paulo, 1970, pg. 95. DL. n. 48, de 18.11.1966 e DL 685, de 17.7.1969.

25. Constituição Federal de 1969 , arts. $51,52,53,54,55$ e 57 .

26. P. ex., L. 4.728, de 14.7.1965, arts. $2 \circ, 3 \circ, 70^{\circ}, 8^{\circ}, 9^{\circ}, 10^{\circ}$ e $14 . \mathrm{L}$. 4.595 , de 31.12 .1964 , arts. $3^{\circ}, 4^{\circ} 9^{\circ}$ e $10^{\circ}$ L 4.829 de 5.11 .1965 arts. 4 o e 6 ?. DL. 427, de 22.1.1969 e D. 64.156, de 4.3.1969. rante dos tempos modernos. Para atenderem-se as pressões econômicas, sacrificam-se não raro a clareza dos textos, a harmonia das disposições e a própria segurança do mundo das relações jurídicas. Em última análise esta é também uma aspiração pragmática, talvez de valor não inferior àquelas outras.

17. De tudo quanto resumidamente se procurou relembrar nota-se a transcendental importância que o Direito Comercial e seus problemas passaram a ter no mundo contemporâneo. Do que se expôs, está a ver-se, com nitidez, a aceleração dos acontecimentos no setor. $O$ país vive momento decisivo de sua História, no ângulo nacional, político e jurídico, em que se processa a transformaça o de uma sociedade tradicional para uma organização apta a usufruir as vantagens dos chamados juros compostos. (27)

Não é preciso muita imaginação para perceber que, mantido o sistema de ordem vigente, novas e importantíssimas modificaçőes jurídicas aparecerão referentes à matéria comercial. Talvez não seja êste o momento propício para fazerem-se as grandes codificaçōes, em que se cristalizam sistemas de alevantada simetria. Se os Códigos de Direito Privado francêses do comêco do século passado, ainda sobrevivos em linhas fundamentais, tivessem sido promulgados dez anos antes, provàvelmente não teriam tido mais que um decê nio de vigência. Semelhantemente, é esta época mais de semear do que de colher, no mundo vivo do Direito Comercial. As formas mais definitivas, na relatividade de todos os fatos humanos, só poderão ser engendradas depois do vendaval, quando as instituições sociais e políticas melhor se cristalizarem em moldes adequados. Is so não quer dizer que se não aprimorem, tècnicamente, nossas leis. Elas podem sair dos prelos legislativos mais meditadas, mais excelentes, menos contraditórias. $\AA$ assessoria dos que sabem jamais será entrave à obra fecunda dos que dirigem e resolvam. E a tarefa jurídica deve ser excelentemente desempenhada para chegar-se a excelência das relações de convivência humana. $\mathrm{O}$ aprimoramento da execução dessa tarefa é, pois, um objetivo revolucionário no mais amplo e puro e ideal dos sentidos, e não dos menos importantes.

27. W.W. Rostow, Etapas do Desenvolvimento Econômico, cit., pg. 20 G. Ripert, Traité Elêmentaire, cit. pg. 14; Luiz Carlos Barbosa Lessa, Nova História do Brasil, P.Alegre, 1967; pg. 203. 